\title{
The influence of eye movements on a new type of apparant visual movement'
}

JOSEPH H. MCFARLAND

ANTIOCH COLLEGE

When the sides of a contour triangle are sequentially presented, Ss report a sequential "flow" of brightness within the sides or a sequential "growth" of the sides. Modal report of this movement occurs in all three sides when the interside intervals are equal and $100 \mathrm{msec}$. Increasing the probability of contour scanning eye movements leads to an increase in this type of apparent visual movement.

From studies dealing with beta and gamma movement, it has been argued that eye movements do not influence apparent visual movement (Bartley, 1963; Guilford \& Helson, 1929; Hulin \& Katz, 1934; Wertheimer, 1912). A type of apparent visual movement is reported here which is influenced by eye movements. This type of apparent visual movement, similar to both beta and gamma, was noted by Ss in a number of studies which employed a method of sequentially presenting the sides of a contour triangle (McFarland, 1963, $1964 \mathrm{a}, \mathrm{b}, 1965)$. Ss frequently reported "flow" or "growth" in one or several of the lines, viz., "the line appears in its entirety all at once but within the line there is a brightness which flows from one end to the other" or "one end of the line appears and then grows into the complete line." Ss also reported that "flow" and "growth" occurred from both ends toward the middle of a line or the reverse.

Method

To test whether eye movements affect this type of movement, one of three observation instructions is employed for each of three independent groups of eight Ss. These instructions are selected on the assumption that they differentially affect the probability of contour scanning eye movements during observation: (a) "fixate the small red light," (b) "try and look straight ahead," (c) "try and scan the lines."

The stimulus is an equilateral, contour triangle (Fig. 1A). Sides are presented for $10 \mathrm{msec}$. each in CCW sequence, 123 . The two inter-side intervals are maintained equal and varied on different trials from 0-300 msec. in 25 msec. steps. Ss are dark adapted for $10 \mathrm{~min}$. and receive five trials on both an ascending and a descending series at each interside interval, a total of 130 trials for each $\mathrm{S}$ (see McFarland, 1965, for details).

\section{Results}

There were reports of "flow" or "growth" on 20\% of the total 3,120 trials for the three groups. Movement was reported in one, two, and three sides, either unidirectional or bidirectional. Three types of unidirectional movement occurred: $\mathrm{CCW}$, movement com-
A
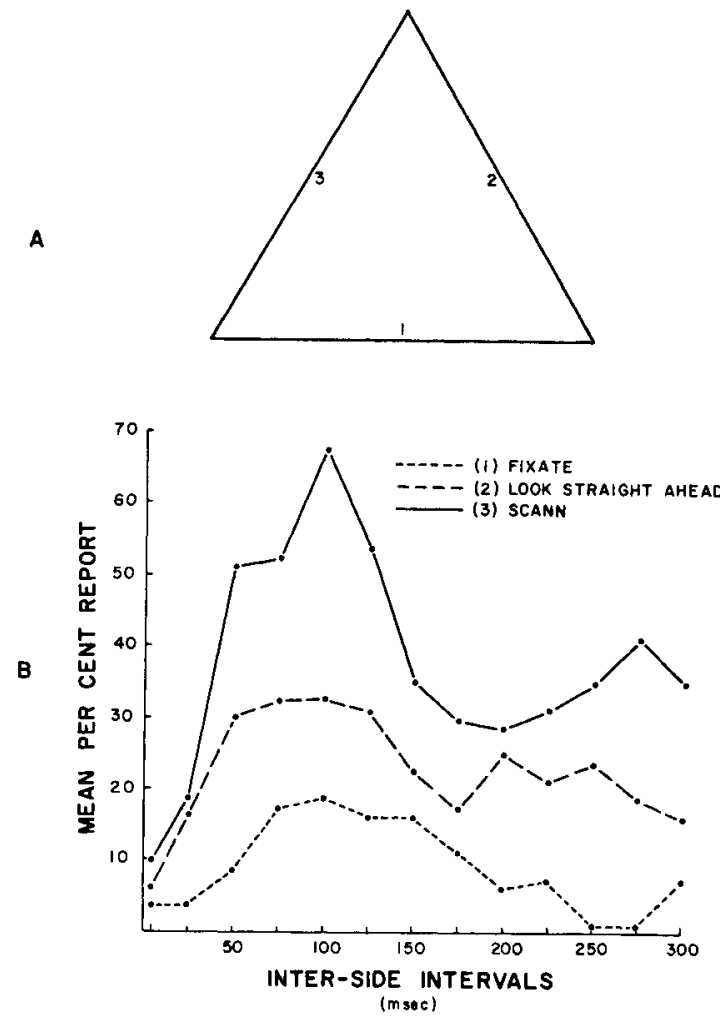

Fig. 1A. The stimulus is presented straight ahead, at eye-level, in a fronto-parallel plane, 17 in. from the $S$. Each side is 1 degree in length and approximately .44 $\mathrm{ft}$. lamberts. For group 2, the red fixation light appears at the center of the triangle. B Mean $\%$ movement report for the three observation groups as a function of inter-side intervals.

menced at the left end of side 1 and proceeded to the right, or commenced at the bottom of side 2 and proceeded up, or commenced at the top of side 3 and proceeded down; $\mathrm{CW}$, the reverse of $\mathrm{CCW}$; and $\mathrm{CCW}$ and $\mathrm{CW}$, a combination. Two types of bidirectional movements occurred: from the center of the line to the ends; from the ends of the line to the center. Bidirectional movement was always, when reported in more than one line, CCW and $\mathrm{CW}$.

The modal report was $\mathrm{CCW}$, unidirectional movement $(F=59.58, p<.01)$ in all three sides $(F=2.97$, $p<.01)$ at an inter-side interval of $100 \mathrm{msec} .(F=2.86$, $p<.01)$. At this inter-side interval, over $50 \%$ of the reports from other Ss are that some of the sides appear unjoined at their ends and the sides appear in perfect succession (Mc Farland, 1965).

Effects of observation instructions on all movement 
Table 1. Types of movement reports as a function of observation instruction (frequency).

Unidirectional movement Bidirectional movement

\begin{tabular}{lrrrr} 
& \multicolumn{2}{c}{ Unidirectional movement } & \multicolumn{2}{c}{ Bidirectional movement } \\
\hline CCW & $C W$ & CCW and CW & $\begin{array}{r}\text { Combined center- } \\
\text { ends and ends-center }\end{array}$ \\
\hline Fixate & 84 & 10 & 4 & 0 \\
Straight ahead 167 & 7 & 5 & 56 \\
Scan & 158 & 39 & 9 & 22 \\
\hline
\end{tabular}

reports can be seen throughout the range of inter-side intervals tested $(F<1.00)$ (Fig. 1B). Instructions have their particular effect on the direction and type of movement (Table 1). Both "try and look straight ahead" and "try and scan the lines" increases the report of CCW, unidirectional movement ( $F=5.21, p<.01)$. Instructions to "try and scan the lines" also increases the report of CW, unidirectional movement $(F=6.80, p<.01)$. Discussion

In considering these effects of observation instructions, it is evident there are two avenues whereby an increase in contour scanning eye movements could lead to the observed increases in this type of apparent visual movement. First, eye movements could displace the stimuli on the retina; and, second, signals from central efferent and/or pheripheral afferent structures of the extra-ocular motor system could interact with retinal signals (Grüsser \& Grússer-Cornehls, 1961). As eye movements are not monitored in the present experiment, however, a clear-cut decision in this regard is not possible. On the basis of the present experiment, it can only be said that, since the modal frequency of this type of movement occurs when inter-side intervals approximate the latency for a saccadic eye movement (Bartz, 1962; Ditchburn \& Ginsborg, 1953; Nachmias, 1959; Ratliff \& Riggs, 1950; Tinker, 1953; Westheimer, 1954), it is likely that when eye movements do occur, they occur during the interside intervals when no side is visible. If future work shows that this is indeed the case, then it would seem plausible to argue that signals from central efferent and/or peripheral afferent structure of the extra-ocular motor system are interacting with retinal signals at some site within the nervous system to produce the increase in this type of movement. The plausibility of such an argument is enhanced by the fact that interaction of extra-ocular motor and retinal signals has already been found to affect the visibility of retinal signals (McFarland, 1964c).

\section{References}

Bartley, S. H. Vision. Hafner: New York, 1963, 176-177.

Bartz, A. Eye-movement latency, duration, and response time as a function of angular displacement. J. exp. Psychol., 1962, 64, 318-324.

Ditchburn, R. W., \& Ginsborg, B. L. Vision with a stabilized retinal image. Nature, $1952,170,36-37$.

Guilford, J. P., \& Helson, H. Eye movements and the phi phenomenon. Amer. J. Psychol., 1929, 51, 595-606.

Ginsborg, B. L. Small involuntary movements of the eye. Brit. J. Opthal., 1953, 37, 746-754.

Grüsser, o. J., \& Grüsser-Cornehls, Ursula. Reaktionsmuster einzelner Neurone in Geniculatum laterals und visuellen Cortex der Katze bei Reisung mit optokinetischen streifenmustern. In R. Jung and H. Kornhuber (Eds.), The visual system: neurophysiology and psychophysics. Springer-Verlag: Berlin, 1961.

Hulin, W. S., \& Katz, D. Eye movements and the phi phenomenon. Amer, J. Psychol., 1934, 46, 332-334.

McFarland, J. H. Some evidence bearing on visual form perception as a process of temporal integration. Eastern Psychological Association Meetings, April 11-13, 1963, New York.

McFarland, J. H. The effect of stimulus-guided eye movements on visual form recognition. Eastern Psychological Association Meetings, April 16-18, 1964a, Philadelphia, Pa.

McFarland, J.H. Some evidence bearing on operations of "analysis" and "integration" in visual form perception by humans. Symposium on Models for the Perception of Speech and Visual Form. 11-14 November, 1964b, Boston, Mass. (in press)

McFarland, J. H. Extra-ocular feedback: a factor in binocular rivalry. Percept. mot. Skills, 1964c, 19, 56.

McFarland, J. H. Sequential part presentation: A method of study ing visual form presentation. Brit. J. Psychol., 1965, in press.

Nachmias, J. Two dimensional motions of the retinal image during monocular fixations. J. Opt. Soc. Amer., 1959, 49, 901-908.

Ratliff, F., \& Riggs, L. A. Involuntary motions of the eye during monocular fixation. J. exp. Psychol, 1950, 40, 687-701.

Tinker, M. A. Recent studies of eye movements in reading. Psychol. Bull., 1958, 55, 215-231.

Westheimer, G. Mechanisms of saccadic eye movements. Amer. Med. Ass. Arch. Opthal, 1954, 52, $710-724$.

Wertheimer, M. Experimentelle Studien uber das Schen von Bewegung. Z. Psychol, 1912, 61, 161-265.

Note

1. This study was supported in part by National Institutes of Health Grant M6403(A), U. S. Public Health Service. 